\title{
Sobre el poder y sus regularidades. Michel Foucault y Pierre
}

\section{Bourdieu}

\author{
Flavio Guglielmi (UNNE) \\ Mail : nietajj@yahoo.com.ar
}

\begin{abstract}
This article aims to establish a comparison in the way of analyzing power in Pierre Bourdieu and Michel Foucault. Both researchers are from different academic traditions but arrive at theoretical constructs with similitudes. In both authors power relationships are built when certain individuals may affect the actions of others. This relationship implies an imposition developed from an inequality or distinction (of goods, skills, authority, etc.), administered from an economy that manages it in an optimal way (although up to each individual case to establish what is considered "optimal"), and responds to a strategy in a game of action and reaction between relatively free agents.
\end{abstract}

Keywords

Power. Strategy. Economy. Freedom

\section{Resumen}

El presente artículo pretende rescatar ciertas notas y modos de analizar el poder en Pierre Bourdieu y Michel Foucault, investigadores que parten de tradiciones académicas diferentes pero que arriban a construcciones teóricas que guardan similitudes. En líneas generales, puede establecer que en ambos autores las relaciones de poder se construyen cuando ciertos individuos pueden afectar las acciones de otros. Dicha relación implica una imposición por parte de un sujeto o grupo que se desarrolla a partir de una desigualdad o distinción (sea de bienes, capacidades, autoridad, etc.); la misma se encuentra administrada desde una economía que permite gestionar los medios para actuar de un modo óptimo (aunque corresponde a cada caso particular establecer lo que se considera óptimo), y responde a una estrategia como una estimación en un juego 
Nuevo Itinerario Revista Digital de Filosofía ISSN 1850-3578 2015 - Vol. 10 - Número X Resistencia, Chaco, Argentina

de acción y reacción entre agentes relativamente libres que no agota la totalidad de las acciones posibles.

\section{$\underline{\text { Palabras claves }}$}

Poder. Estrategia. Economía. Libertad

El presente artículo pretende rescatar ciertas notas y modos de analizar el poder en Pierre Bourdieu y Michel Foucault, investigadores que parten de tradiciones académicas diferentes pero que arriban a construcciones teóricas que guardan similitudes. Es posible indicar dos precauciones con respecto al modo de abordar la temática por parte de los autores. La primera de ellas es metodológica, y permite guiar el modo de presentar algunos conceptos capitales y sus problematizaciones. En las obras de los filósofos franceses, el estudio del poder no responde tanto a un elemento programático explícito, sino a una orientación, cierto humor (pathos) o actitud presente en el modo de teorizar sobre la temática. Es necesario tener presente que las mismas expresan indicaciones o modos posibles de investigación antes que conceptualizaciones definitivas e invariables. De este modo, las nociones que presentan responden más a conjeturas útiles que adquieren importancia por su funcionalidad, antes que por ser resultados finales.

La disposición mencionada en el párrafo anterior puede ser rastreada en diferentes pasajes de los autores de manera implícita, pero son representativas dos instancias manifiestas. Foucault comenta que en la base de su análisis teórico se encuentra un imperativo que funciona como un indicador táctico, cuyo interés se centra en mostrar algunos “(...) puntos clave, algunas líneas de fuerza, algunos cerrojos y 
Nuevo Itinerario Revista Digital de Filosofía ISSN 1850-3578 2015 - Vol. 10 - Número X Resistencia, Chaco, Argentina

algunos obstáculos". 1 Posteriormente, el autor sugiere que sus argumentaciones o análisis no sean considerados desde una administración de la verdad, sino que, en última instancia, respondan a un régimen estético. Inclinarse por una indicación o detestar otra, desconfiar de una postura o afirmarla responde a modos particulares de evaluar los discursos y no a parámetros canónicos. De este modo, corresponde al lector tomar dichas indicaciones y otorgarle su eficacia pertinente según los campos de estudio o los espacios de lucha donde pretende hacerlos valer.

En Bourdieu puede encontrarse un carácter procedimental similar cuando el autor presenta un estudio sobre el poder simbólico como una forma de balance que no debe tomarse como "(...) una historia -incluso escolar- de las historias del simbolismo, ni menos aún como una suerte de reconstrucción seudo-hegeliana de los pasos que habrían conducido, por superaciones sucesivas, hacia la teoría final". ${ }^{2}$ Los estudios que abordan dicha temática presentan un carácter no definitivo, sea por la imposibilidad de formular dicha teoría o por la incapacidad de presentar una misma línea de investigación que recupere y supere a las anteriores en un mismo movimiento. Resta preguntarse por el modo de valorar dicho modo de investigación y si, al igual que en Foucault, la utilidad del mismo representa una instancia con mayor significatividad que los parámetros de formulación de la verdad. Para ello, es posible trazar un paralelo entre modo de abordar los estudios del poder y el hábitus ya que, al presentar una definición del segundo, Bourdieu destaca su carácter transitorio y que “(...) tal vez es válido ante todo por los falsos problemas y las falsas soluciones que elimina, las cuestiones que permite resolver de mejor manera o bien resolver, y las dificultares propiamente científicas que hace emerger". ${ }^{3}$ Se trata entonces de un abordaje que permite resolver de

\footnotetext{
${ }^{1}$ Foucault, Michel. Seguridad, Territorio, Población. Trad. Horacio Pons. Fondo de Cultura Económica, Bs As, 2006. p. 18. También es posible comentar la indicación de la teoría como una "caja de herramientas" que Foucault y Gilles Deleuze presentan en una entrevista: "Es preciso que sirva, que funcione. Y no para uno mismo. Si no hay personas para utilizarla, comenzando por el teórico mismo, que deja entonces de ser teórico, es que no vale nada, o que el momento no llegó aún". Foucault, Michel y Deleuze, Gilles. "Los intelectuales y el poder". Trad. Fernando Álvarez Uría y Julia Varela. En: Foucault, Michel. Obras Esenciales. Madrid, Paidos, 2010, p. 435. Por último, es sugerente la siguiente indicación de Foucault con respecto a su modo de abordar la tradición de autores en filosofía: "Yo, a las gentes que amo, las incorporo. La única marca de reconocimiento que se puede testimoniar a un pensamiento como el de Nietzsche es precisamente utilizarlo, deformarlo, hacerlo chirriar, llevarlo al límite. Mientras tanto, los comentaristas se dedican a decir si se es o no fiel al texto, algo que carece del menor interés". Foucault, Michel. "Entrevista sobre la prisión: el libro y su método". Trad. Fernando Álvarez Uría y Julia Varela. En: Obras Esenciales. Op. Cit., p. 610

2 Bourdieu, Pierre. "Sobre el poder simbólico", en: Intelectuales, política y poder. Trad. Alicia B. Gutiérrez. Bs As, Eudeba, 2005, p 65. Las cursillas son del texto original.

${ }^{3}$ Bourdieu, Pierre. El sentido práctico. Trad. Ariel Dilon. Bs As, Siglo XXI, 2010, nota № 2. p. 86
} 
Nuevo Itinerario Revista Digital de Filosofía ISSN 1850-3578 2015 - Vol. 10 - Número X Resistencia, Chaco, Argentina

mejor manera problemas y obstáculos antes que de concluirlos de manera definitiva, sin dejar de reconocer otras dificultades que puedan surgir.

La segunda precaución también apunta a desestimar una teoría general e invariable del poder, pero no por cuestiones de método sino por las características del propio objeto de estudio. En ambos autores las diferentes formas de poder responden a instancias tácticas heterogéneas que presentan regularidades; ${ }^{4}$ lo cual implica que los distintos modos en que el poder se presenta se encuentran referidos a distintas prácticas concretas que exceden la posibilidad de englobar íntegramente en una misma teoría. Las investigaciones sobre la temática deben renovarse continuamente según el ámbito social que se esté señalando y sus particularidades. Ello refuerza la necesidad de marcar un carácter indicativo en los postulados, como una primera orientación o manera de abordar una praxis antes que a su determinación.

\section{Pierre Bourdieu. El poder simbólico y su regularidad económica}

Bourdieu recobra una analogía que realiza Bertrand Rusell entre el poder y la energía en tanto objeto de estudio de la sociología y la física respectivamente. El autor británico señala que ambos existen bajo muchas formas, no siendo ninguna de ellas considerada como subordinada a algún modo originario y que, por ende, tampoco se presenta un género primitivo que es sustento de las otras formas. ${ }^{5}$ Gracias a ello podemos considerar al poder en constante transformación o bajo diferentes modalidades, sin remitirlo a una sola causa desde donde se desprenden y a las cuales se subordinan el resto de sus expresiones. Si bien dicha comparación es significativa, ya que descarta la idea de centros de poder y ordenaciones jerárquicas definitivas, Bourdieu subraya que de dicha comparación no obtuvieron consecuencias reales en las teorías sociales.

Extendiendo la analogía de Rusell, puede establecerse que el término energía, si bien se enuncia en singular, connota una pluralidad de sucesos que difícilmente tengan características similares. Lo mismo ocurre con el poder, siendo su formulación más correcta las formas de poder. En ambos casos, no se presentan de manera pura o

\footnotetext{
${ }^{4}$ Este punto será analizado y detallado con posterioridad en el presente trabajo, sirva ahora simplemente como un señalamiento.

${ }^{5}$ Cfr. Bourdieu, Pierre. El sentido práctico. Op. Cit. p. 85 Nota. 1
} 
Nuevo Itinerario Revista Digital de Filosofía ISSN 1850-3578 2015 - Vol. 10 - Número X Resistencia, Chaco, Argentina

remitiendo a una forma original sino que expresan modalidades. Para lograr registrarlas es preciso encontrar estabilidades que permitan fijarlas e identificarlas. La apuesta de Bourdieu al respecto es encontrar regularidades en las prácticas sociales, es decir, en la praxis de los agentes con y en el mundo social, sin dejar de señalar su pluralidad histórica.

Las prácticas son objetivamente reguladas y regulares bajo el conjunto de disposiciones duraderas y transferibles que constituyen el hábitus. ${ }^{6}$ Es precisamente el hábitus lo que permite advertir regularidades y así indagar una economía general de las prácticas, es decir, establecer que las prácticas atienden a una lógica económica capaz de ser generalizable en una teoría adecuada a las acciones de cada espacio social. Se considera al conjunto de las acciones, incluso las que se presentan como gratuitas o desinteresadas en el sentido mercantil, invariablemente dirigidas o conducidas a algún tipo rendimiento y utilidad concreta. En este punto se conjugan tanto los aspectos materiales como aquellos simbólicos que presentan mayor dificultad al momento de ser cuantificados. Al decir de Bourdieu, se trata de una ciencia de las prácticas que abandona la dicotomía entre lo económico y no económico, considerando a la totalidad de las mismas “(...) orientadas hacia la maximización del beneficio, material o simbólico". 7

Las prácticas pueden ser registradas como regularidades tendientes a una administración de formas de capitales que son al mismo tiempo heterogéneos pero relativos entre sí. Bourdieu retoma la analogía de la energía y poder, restableciéndola entre capital y energía. El capital se presenta así bajo diferentes formas o especies, siendo el económico simplemente una de ellas frente a otras como el político o el de fuerza de combate. Al igual que las riquezas materiales, los capitales pueden presentarse bajo distintos modos cuyas utilidades “(...) no tienen su justificación "en sí mismas”, es decir en su función "económica" o "técnica", y (...), en su extremo, pueden ser totalmente inútiles (...),${ }^{8}$ Es en su relación que los mismos adquieren una función e

\footnotetext{
${ }^{6}$ Desarrollaremos otras características del hábitus con posterioridad. El mismo puede ser presentado provisoriamente como un sistema de “(...) estructuras estructuradas predispuestas a funcionar como estructuras estructurantes, es decir, como principio generadores y organizadores de prácticas y de representaciones que pueden ser objetivamente adaptadas a su meta sin suponer el propósito consciente de ciertos fines ni el dominio expreso de las operaciones necesarias para alcanzarlos (...)". Ibíd. p. 86

${ }^{7}$ Ibíd. p. 195

${ }^{8}$ Ibíd. p. 212. Las comillas corresponden al texto original
} 
Nuevo Itinerario Revista Digital de Filosofía ISSN 1850-3578 2015 - Vol. 10 - Número X Resistencia, Chaco, Argentina

importancia, y no considerados de manera aislada. Algunos capitales forman parte de los gastos considerados como demostrativos, es decir, representa un medio que sirve para hacer conocer y reconocer el poder de manera visible y pública. Pero otros son destinados a fines productivos (o simbólicos) lo cual significa, en líneas generales, que contribuyen a la legitimación y a la reproducción de jerarquías que establecen modos de dominación. Los capitales van a conjugarse tendiendo a buscar tanto la creencia como la obediencia “(...) de manera duradera y al menor costo", 9 dando lugar a una economía de prácticas que administra desigualdades (sea para establecerlas, mantenerlas, producirlas, transformarlas, etc.) de un modo óptimo.

Entre las diferentes formas de capitales, su manera simbólica adquiere una importancia relevante en su economía ya que permite producir efectos tangibles sin un gasto manifiesto de recursos. La misma faculta a un grupo dominante " (...) constituir lo dado por la enunciación de hacer ver y de hacer creer, de confirmar o de transformar la visión del mundo y, por ello, la acción sobre el mundo, por lo tanto del mundo (...)." ${ }^{10}$ El capital simbólico estable un modo de construcción de la realidad, un orden o sentido en cada ámbito social, y por ende orienta las prácticas que se desarrollan en los mismos. La constitución de un espacio social homogéneo se produce por una imposición que es desconocida en su arbitrariedad y es reconocida como un orden natural. Sin embargo, ello no implica que abandone su carácter violento, sino que simplemente cambia su carácter, como una forma simbólica de dominación “(...) más suave, invisible, desconocida en cuanto tal (...) el modo de dominación más económico (...”."11

Las acciones violentas como forma de dominación implican una recreación continua y expresa, debido a ello son considerablemente costosas “(...) lo cual hace que el medio devore al fin y que las acciones necesarias para asegurar la duración del poder contribuyan a su fragilidad. Hay que gastar fuerza para producir (...) y ocurre que una gran parte de la fuerza se pierde en ello". ${ }^{12}$ La violencia simbólica se muestra así como más efectiva y económica, al establecer modos de dominios estables y duraderos con un menor gasto de recursos. Vale destacar que el reconocimiento de la arbitrariedad en la imposición, como un eufemismo de las relaciones de fuerzas presentes entres los

\footnotetext{
${ }^{9}$ Ibíd.

${ }^{10}$ Bourdieu, Pierre. "Sobre el poder simbólico", op. cit. p. 71

${ }^{11}$ Bourdieu, Pierre. El sentido práctico. Op. Cit. p. 205

${ }^{12}$ Ibíd. p. 212
} 
Nuevo Itinerario Revista Digital de Filosofía ISSN 1850-3578 2015 - Vol. 10 - Número X Resistencia, Chaco, Argentina

diferentes agentes, implica una disminución de la potencia simbólica por parte de los grupos dominantes aunque no necesariamente implica desobediencia o una sublevación.

La regularidad económica en las prácticas se organiza como una forma de estrategia particular en los individuos, ya que se establecen como un juego de acción y reacción entre agentes o grupos de agentes constituidos bajo un determinado hábitus común. En primera instancia, se presenta como un cálculo que partiendo de ciertas acciones un agente puede anticipar como repercusiones en otro participante del mismo campo. Se organiza así una estratagema concebida como una manera de actuar frente a un porvenir probable. Dichas anticipaciones se encuentran fuertemente condicionadas por las primeras experiencias y orientaciones prácticas en cada forma de dominación particular. Se trata de un cálculo y una estrategia que en parte responde a un condicionamiento por contextos de existencia semejantes. Debido a ello, y al decir de Bourdieu, enfrentamos “(...) estrategias, sin ser el producto de una verdadera intención estratégica (...)"13 y cálculos “(...) por fuera de todo cálculo", ${ }^{14}$ respondiendo a disposiciones en los esquemas de percepción y apreciación antes que a una acción deliberada.

Las evaluaciones de los agentes se presentan, antes que como una técnica explícita o una obediencia a determinadas reglas, como “(...) el arte de estimar y de aprovechar las probabilidades, la aptitud para articular el porvenir mediante una suerte de inducción práctica o inclusive de jugar a lo posible contra lo probable a través de un riesgo calculado (...)". ${ }^{15}$ Ocurre que si bien las prácticas de cada campo condicionan las posibles acciones futuras no por ello las determinan, ya que admite la elaboración de esquemas de pensamientos y percepción libres pero siempre relativos a los límites de sus condiciones de producción histórica y social. Se está frente a un hábitus que permite “(...) como todo arte de invención (...) producir prácticas en un número infinito, y relativamente imprevisibles (como las correspondientes situaciones), pero limitadas no obstante en su diversidad". ${ }^{16}$ Percibidas como las conductas razonables, esperables o de sentido común, los condicionamientos objetivos presentes en el hábitus son los que permiten descartar las acciones no admitidas o incompatibles con las mismas. Se funda

\footnotetext{
${ }^{13}$ Ibíd. p. 100

${ }^{14}$ Ibíd. p. 87

${ }^{15}$ Ibíd. p. 103

${ }^{16}$ Ibíd. p. 90. Las cursivas corresponden al texto original
} 
Nuevo Itinerario Revista Digital de Filosofía ISSN 1850-3578 2015 - Vol. 10 - Número X Resistencia, Chaco, Argentina

así la posibilidad de éxito en las estimaciones de los agentes y también un ahorro de sentido en cuento a la diversidad de evaluaciones posibles.

Al estar diagramadas dentro de las disposiciones del hábitus, la dominación simbólica no se presenta como un elemento externo y opuesto a los agentes que la soportan. Por el contrario, implica “(...) una forma de complicidad que no es ni sumisión pasiva a una coerción exterior, ni adhesión libre a los valores". ${ }^{17}$ Es decir, son posibles gracias a que una persona se encuentra predispuesta a experimentarlas o aceptarlas. La praxis de los individuos no son relativas a una dicotomía libertadcoerción, ello implicaría una forma superficial de dominio que requiere un acto de intimidación recurrente. Se establece de modo más profundo, sin necesidad de recurrir a coacciones o intenciones consientes, inscribiéndose en los esquemas de percepción propios de cada campo social.

Es importante remarcar que las interacciones establecidas entre los agentes, mediante esta combinación de acción y reacción, no se desarrollan de manera teleleológica y mecanicista. Ello implicaría no solamente desconocer la relativa imprevisibilidad de las prácticas, sino también afirmar que los actores poseen una información perfecta sobre las competencias y preferencias de los otros participantes, reduciendo las articulaciones a simples secuencias de acciones programadas. Sin embargo, el hábitus permite trazar estrategias exitosas en tanto que las condiciones objetivas que lo forjaron, y que permitieron que sea posible establecer una experiencia, permanezcan similares. Se presume así una forma particular de lo posible y no la totalidad de lo posible. En ello radica la apuesta y el riesgo en el arte de estimar. Por eso las tácticas resisten un abordaje universal o generalizado y se encuentran doblemente condicionadas: por las circunstancias de producción del hábitus y por los escenarios de su funcionamiento. ${ }^{18}$

En su teoría de la práctica en cuanto práctica, Bourdieu se distancia tanto de un objetivismo, donde las estructuras sociales son exteriores y se imponen a los individuos o a los grupos, así como también de un subjetivismo, que desconoce las relaciones objetivas o necesarias para actuar. La praxis se muestra como un ámbito donde ambos se configuran mutuamente al relacionar los aspectos incorporados con un mundo social

\footnotetext{
${ }^{17}$ Bourdieu, Pierre. ¿Qué significa hablar? Economía de los intercambios linguisticos. Trad. Esperanza Martínez Pérez. Madrid, Akal, 1999. p. 25

${ }^{18} \mathrm{Cfr}$. Bourdieu, Piere. El sentid práctico. Op. Cit. p.p. 100 y 101
} 
que impone su “(...) presencia, con sus urgencias, sus cosas por hacer y por decir, que comandan de manera directa los gestos o las palabras (...)" ${ }^{19}$ Esto significa que se deja de lado una separación entre los sujetos y las formas de poder, siendo ambos un producto de la praxis social.

Un espacio particular donde se actualizan las relaciones entre los distintos actores sociales, respondiendo también a una economía de intercambios, es el que se constituye en las relaciones de comunicación. Bourdieu propone tomar el habla como una forma de acción que, como toda praxis, conjuga disposiciones incorporadas y condicionamientos objetivos. Al respecto, aclara que si bien tiene características naturales y por lo tanto compartidas entre todos, "Lo raro no es, pues, la capacidad de hablar, que por estar inscrito en el patrimonio biológico es universal, y, por tanto, esencialmente no distintiva, sino la competencia necesaria para hablar la lengua legítima, una competencia que, al depender del patrimonio social, reexpresa las distinciones sociales $(\ldots) "{ }^{20}$ La posibilidad de comunicarse enlaza, por una parte, un hábitus lingüístico entendido como una competencia socialmente moldeada para expresarse (hablar y decir) de manera adecuada ante una determinada situación. No existe un límite a las formas posibles de enunciación, ya que el lenguaje muestra tener una capacidad generativa sin restricciones en cuanto a su gramaticalidad. ${ }^{21}$ Pero las mismas, por otro lado, están condicionadas ya que las disposiciones se conectan con un sistema de sanciones y censuras específicas que restringen los modos de hablar con sentido por parte de los grupos dominantes. Se denomina a dicho sistema mercado lingüístico. $^{22}$

Hablar es más que enunciar signos para comunicar o expresarse, ya que los discursos también buscan ser valorados o apreciados (singo de riqueza) y ser creídos u obedecidos (signo de autoridad). De este modo, “(...) el intercambio lingüístico es también un intercambio económico (...) entre un productor, provisto de un cierto capital lingüístico, y un consumidor (o un mercado), apto para procurar un cierto beneficio material o simbólico". ${ }^{23}$ Las palabras adquieren valor y sentido al vincularse con un

\footnotetext{
${ }^{19}$ Ibid. p. 85

${ }^{20}$ Bourdieu, Pierre. ¿Qué significa hablar? Economía de los intercambios linguisticos. Op. Cit. p. 29. Las cursivas corresponden al texto original

${ }^{21}$ Al respecto "No hay nada que no pueda decirse y puede decirse la nada. En la lengua, es decir, en los límites de la gramaticalidad, se puede enunciar todo". Ibid. p. 15

${ }^{22}$ Sobre el mercado lingüístico y el hábitus lingüístico Cfr. Ibíd. p.p 11 y 12

${ }^{23}$ Ibíd. p 40
} 
Nuevo Itinerario Revista Digital de Filosofía ISSN 1850-3578 2015 - Vol. 10 - Número X Resistencia, Chaco, Argentina

mercado que puede tazarlo. Al interactuar, los diferentes agentes intentan imponer un criterio de apreciación que beneficie sus productos lingüísticos. De este modo, la estructura social y las relaciones de fuerzas se conjugan con las prácticas lingüísticas para establecer un hablar con eficacia simbólica, con valor social y tanto práctica como teóricamente competitivo.

No basta que los discursos sean gramaticalmente correctos, también deben estar revestidos de cierto valor social para que sean escuchados o creídos; allí interviene el mercado lingüístico. Por otro lado, es el habitus lingüístico lo que permite prever el comportamiento de dicho mercado y las leyes que determinan sus valores discursivos mientras no cambien las condiciones de producción y recepción del mismo. De este modo es posible anticipar ciertos beneficios probables y la aceptación de los signos lingüísticos. Ello se produce sin recaer en un cálculo racional que maximice los beneficios simbólicos, sino atendiendo a disposiciones incorporadas en el propio hábitus. $^{24}$

La constitución de un mercado también permite componer un capital lingüístico, el cual surge de una rivalidad objetiva y competitiva entre los hablantes. Dicho capital pretende generar una distinción en las prácticas lingüísticas, entiendo que la misma busca generar un beneficio a su poseedor al atribuirle valor y credibilidad frente a otros agentes o discursos. Al igual que el mercado económico, no existen condiciones de competencia equivalentes para todos los hablantes, sino que la misma depende de la posición ocupada en la estructura social. Las utilidades de la distinción se distribuyen de manera correspondiente a las cualificaciones lingüísticas desiguales de los locutores $\mathrm{u}$ oferentes de productos discursivos. ${ }^{25}$

De modo similar al anticipo práctico de los beneficios, también pueden estimarse las sanciones del propio mercado lingüístico. La producción de discursos se encuentra fuertemente ajustada a las condiciones de recepción. Se producen entonces continuas formas de correcciones o autocensura por parte de los agentes que buscan aumentar su eficacia lingüística. Las mismas afectan no sólo “(...) la manera de hablar, la elección del lenguaje (...) o del "nivel” del lenguaje, sino también lo que podrá o no

\footnotetext{
${ }^{24}$ cfr. p.p. 50 y 51

${ }^{25}$ Cfr. Ibíd. p.p. 29 y 30
} 
Nuevo Itinerario Revista Digital de Filosofía ISSN 1850-3578 2015 - Vol. 10 - Número X Resistencia, Chaco, Argentina

podrá decirse". ${ }^{26}$ Los discursos se ven afectados tanto en su estilo como en las temáticas dentro de las cuales puede hablarse con sentido.

Un lenguaje común es el resultado de una imposición por parte de determinados grupo sociales, siendo las palabras válidas para todos los agentes, es decir, tanto para los dominantes y los dominados. Los signos lingüísticos no son neutros ya que conjugan las diferentes posiciones en el espacio social de los locutores, cada uno con sus intenciones e intereses particulares. Pero su eficacia simbólica radica en la posibilidad de ser reconocidos por fuera de un campo limitado de actores y ser aceptados en espacios combinados. Exponer el lenguaje con características imparciales responde a una eufemización de la violencia que intenta “(...) establecer un consenso práctico entre agentes o grupos de agentes dotados de intereses parcial o totalmente diferentes: (...) en el campo ante todo de la lucha política legítima, pero también en las transacciones y en las interacciones de la vida cotidiana". ${ }^{27}$ Presentarlo como una práctica independiente de un mercado, y por ende como algo neutro o desinteresado, corresponde más a una estrategia de dominación que a una posibilidad del propio lenguaje.

\section{Michel Foucault. El poder como agonismo y su regularidad como gobierno}

Frente a los estudios de Bourdieu sobre el poder, el abordaje de Foucault es más disperso y menos sistemático. Es conocida la entrevista otorgada un año antes de su muerte, en 1983, cuando el autor reconoce esta ausencia con respecto a un tratado orgánico vinculado a dicha temática y declara "no tengo tiempo de hacerlo ahora, pero se la podría hacer. En efecto, es necesario que la escriba". ${ }^{28}$ Debe agregarse también que las nociones foucaultianas presentan una menor estabilidad en sus definiciones; las conceptualizaciones responden a un juego de contrastes y oposiciones que surgen en estudios delimitados y específicos. Un término recurrente en el autor como el de soberanía es definido de una manera frente al poder disciplinario en 1977 y de otro

\footnotetext{
${ }^{26}$ Ibíd. p. 51. Las comillas corresponden al texto original

${ }^{27}$ Ibíd. p. 15

${ }^{28}$ Foucault, Michel. Dits et écrits, Gallimard, París, 1994. p. 386. Citado en: Castro, Edgardo. Lecturas Foucaulteanas. Una historia conceptual de la Biopolítica. UNIPE, La Plata, 2011. p. 45. Foucault es interrogado puntualmente por un tratado sobre una forma de poder específica que es el biopoder, pero una posible genealogía del mismo debe incluir en su desarrollo las diferentes formas en que se presenta y por ello abordarlo de manera más extensa.
} 
modo en 1976, cuando se lo opone al discurso de guerra. ${ }^{29}$ Debido a ello se optará por indagar uno de los últimos ensayos específicos de Foucault sobre la temática. ${ }^{30}$

El primer elemento que hace emerger la problemática sobre el poder es el modo de interrogar sobre dicho tema. En este punto, Foucault reconoce que el carácter de la pregunta predispone parte de la respuesta; examinarlo desde una perspectiva clásica buscando el qué y el por qué son cuestionamientos válidos pero pueden llevar a discusiones interminables al suponer que el poder existe bajo una misma naturaleza y origen. El autor señala que estos interrogantes se encuentran cercanos a la metafísica o la ontología, dando entidad a un objeto con propiedades en sí mismo incluso desde antes que sea examinado. Es un problema frecuente que se presenta a los investigadores, incluso antes de iniciar su tarea, ya que parten de un concepto previo y diferente sobre un término que se presenta de modo abarcador y reificante. Frente a ello, Foucault realiza la sugerente hipótesis de considerar que el poder no existe para evitar mayores dificultades en su análisis, disponiendo su indagación desde el cómo actúa. Esta última pregunta permite suspender momentáneamente las anteriores y no se limita a buscar las manifestaciones del poder, sino que se focaliza en esclarecer de manera empírica los medios por los cuales se ejerce y qué ocurre cuando un individuo lo emplea sobre otros. $^{31}$

La primera distinción que surge señala la diferencia entre el poder que se ejerce sobre los objetos y aquel entre individuos. El primero se distingue por una capacidad para modificar, usar, consumir o destruir algún elemento material; dicha destreza se asienta en actitudes inherentes al cuerpo o subyace en instrumentos externos. El segundo se caracteriza por designar relaciones entre partes o por poner en juego relaciones entre individuos o grupos. En términos generales, no es un juego de suma cero donde existe un ganador que se lleva la parte que le corresponde al perdedor, sino un “(...) conjunto de acciones que inducen a unos a seguir a otros". ${ }^{32}$

El autor remarca que si bien las relaciones de comunicación también son formas de actuar de una persona sobre otra, las mismas se distinguen de las relaciones de poder.

\footnotetext{
${ }^{29}$ Cfr. Nosseto, Luciano Ezequiel. Discursos y estrategias. Michel Foucault y la política. Tesis para optar por el título de Doctor en Ciencias Sociales. S/E, Facultad de Ciencias Sociales, Universidad de Buenos Aires, 2010. p. 21

${ }^{30}$ Foucault, Michel. El Sujeto y el Poder. En: Dreyfus, Hubert y Rabinow, Paul. Michel Foucault: más allá del estructuralismo y la hermenéutica. Trad. Rogelio C. Paredes. Nueva Visión, Buenos Aires, 2001.

${ }^{31}$ Cfr. Ibid. p.p. 249 y 250

${ }^{32}$ Ibid. p. 250
} 
Las primeras se presentan como un modo de transmitir información por medio del lenguaje, sea por un sistema simbólico o un conjunto de signos. Pero la producción y circulación de signos tienen consecuencias o efectos en el dominio del poder, sin que el segundo se reduzca a ser un simple aspecto del primero. Es en este sentido que ambas están vinculadas pero no deben confundirse.

Se distinguen entonces tres dominios que no se presentan completamente separados: relaciones de poder, de comunicación y las capacidades. Las capacidades corresponden al campo de las cosas, de la técnica perfecta, del trabajo y las transformaciones de lo real; las comunicaciones al campo de los signos, la reciprocidad y la producción de significados; mientras que el poder responde al campo de la coacción, de la desigualdad y de la acción de unos hombres sobre otros. Por ejemplo, el desarrollo de capacidades objetivas como aprender un oficio involucra necesariamente relaciones de comunicación (información adquirida previamente para hacer el trabajo o compartirlo) y de relaciones de poder (imposiciones de aprendizaje obligatorias o relativamente forzosas en la división del trabajo). ${ }^{33}$

Las relaciones entre estos tres campos “(...) se superponen uno sobre el otro, sosteniéndose recíprocamente entre sí como medios y fines". ${ }^{34}$ Pero no son coordinadas de manera uniforme, constante o equilibradas de manera homogénea. Existen diversas formas, lugares u ocasiones que establecen relaciones de acuerdo a modelos específicos. Foucault enfatiza el hecho de que las relaciones mismas no se presentan bajo una forma natural. Dependiendo las circunstancias analizadas pueden encontrarse jerarquías o preeminencias de unos sobre otros, como cuando priman las articulaciones de poder y obediencia (por ejemplo en las disciplinas de tipo monástico o penitencial), o las actividades terminadas (en disciplinas de los talleres $\mathrm{u}$ hospitales), o las de comunicación (en las disciplinas de aprendizaje). Incluso puede presentarse una saturación entre los tres campos como en la disciplina militar, donde los signos marcan relaciones de poder unidas y calculadas para producir cierto número de efectos técnicos.

Lo expuesto en el párrafo anterior no invalida que las relaciones entre los campos no puedan ser coordinadas, sino que no existe una sola forma de organizarlos. Foucault comenta que de hecho se presentan bloques, en tanto sistemas regulados y concertados, que adaptan tanto las habilidades, como los recursos de comunicación y las

\footnotetext{
${ }^{33}$ Cfr. Ibid. p.p. 250 y 251

${ }^{34}$ Cfr. p. 250
} 
relaciones de poder. Es lo que constituye en líneas generales una disciplina. Por ejemplo las instituciones educativas son un bloque capacidad-comunicación-poder, que asegura el aprendizaje o la adquisición de aptitudes (saber ejercer una profesión), por medio de comunicaciones reguladas (lecciones, preguntas, escalas de valor, etc.) y por medio de una serie de procedimientos de poder (encierro, reprobar como modo castigo, recompensa al tener una buena nota, etc.). ${ }^{35}$

Siendo las relaciones de poder aquellas que se ejercen entre sujetos, resta establecer sus características particulares. Las mismas no se configuran como cualquier tipo de vínculo entre individuos, sino a partir de aquellas acciones que pretender modificar a otras. Foucault despliega tres consecuencias de esta premisa. En primer lugar problematiza la idea de que el poder tenga una entidad o forma concreta universal, como Poder referido con mayúscula o de manera ontológica, ya que únicamente subsiste cuando es puesto en acción. En segundo lugar, rechazando una tesis contractualista, objeta que sea el resultado necesario de un consenso que implique una renuncia a la libertad, una transferencia de derechos o una delegación del mismo de manera individual y colectiva a unos pocos. El consentimiento puede estar presente o no, pero no es ineludible ya que las acciones pueden ser afectadas sin la exigencia de un acuerdo previo. Por último, rechaza la violencia tanto en cuanto la forma primitiva de poder, su elemento oculto o su último recurso. Es decir, no toma a la violencia como naturaleza real del poder que se ve enmascarada mediante estrategias, ya que la misma anula toda relación y la reduce a pasividad o minimiza sus posibilidades productivas.

El ejercicio del poder recurre a la violencia o el consenso, a veces al mismo tiempo, tanto como instrumento o como resultado. Pero ambos elementos son medios que no deben confundirse con las formas de poder. Se trata de una "(...) estructura total de acciones dispuestas para producir posibles acciones: incita, induce, seduce, facilita o dificulta: en un extremo, constriñe o inhibe absolutamente; sin embargo, es siempre una forma de actuar sobre la acción del sujeto, en virtud de su propia acción de ser capaz de una acción". ${ }^{36}$ Esto quiere decir que llevado a un extremo puede resultar una simple imposición y saturar las posibilidades de actuar de un sujeto, pero que le es más propio dirigir las conductas y disponerlas para obtener ciertos resultados.

\footnotetext{
${ }^{35}$ Cfr. p.p. 251 y 252

${ }^{36}$ Ibid. p. 253
} 
Foucault remarca que el término conducta resulta útil para explicar la doble condición de las relaciones de poder. Ya que por un lado representa la conducción de personas por medio de diferentes tipos de coerciones (siendo los individuos conducidos o dirigidos), y también una manera de comportarse dentro de ciertas posibilidades (comportarse o conducirse a uno mismo). La práctica del poder responde a una cuestión de gobierno, siguiendo el amplio significado que tenía dicho último término en el siglo XVI, que nos se agotaba en la estructura estatal o sistema político sino que también designa “(...) la forma en que podría dirigirse la conducta de los individuos o de los grupos: el gobierno de los niños, de las almas, de las comunidades, de las familias, de los enfermos". ${ }^{37}$ Su objetivo no responde únicamente a la sujeción política o económica, ya que incluye disponer un campo posible de acción de los otros. Debido a ello, las relaciones de poder se sitúan bajo un modo de acción singular que es el gobierno, que puede servirse de otros elementos belicosos y violentos, o voluntarios y jurídicos.

La libertad es un componente indispensable para el ejercicio del poder. Suele ser presentada como lo opuesto, mostrándola como algo limitado allí donde se ejerce el poder. Pero, siguiendo las indicaciones de Foucault, su vínculo no es de oposición, sino que implica una interrelación más compleja. Sin el libertad, la relación no es de poder, sino un determinación física de constricción; se produce una saturación de la totalidad de reacciones posibles, por ejemplo, con una persona reducida a la esclavitud y encadenada. Debido a ello una relación de poder se “(...) ejerce solamente sobre sujetos libres que se enfrentan con un campo de posibilidades en el cual pueden desenvolverse varias formas de conducta, varias reacciones y varios comportamientos". ${ }^{38}$ En otras palabras, se despliega en un escenario donde dos o más participantes puedan realmente realizar jugadas. El autor utiliza el término término agonismo para señalar dicha articulación entre individuos o grupos, ya que es una relación de permanente provocación, de recíproca incitación y lucha antes que a un enfrentamiento que paraliza a un contrincante.

Las relaciones de poder pueden ser analizadas a partir de la estrategia elegida para dirigir la conducta de un antagonista, pero el término estrategia se utiliza de tres maneras diferentes que conviene examinar por separado. En primer lugar como medio utilizados para llegar a un fin o racionalidad para llegar a un objetivo. También como

\footnotetext{
${ }^{37}$ Ibid. p. 254

${ }^{38}$ Ibid. p. 254
} 
una manera de obtener ventajas ante otros al actuar en vistas de lo que demás esperan que sean las acciones propias. Finalmente, como los procedimientos para reducir los medios de combate del oponente y forzarlo a abandonar la lucha, obteniendo así una victoria. Los tres tienen en común que una situación de confrontación, sea de juego o guerra, busca reducir al adversario, haciendo imposible la lucha para él y así “(...) la estrategia se define por la elección de soluciones victoriosas". ${ }^{39}$ Las relaciones de poder se vinculan con las estrategias de confrontación, ya que ambas constituyen un medio de acción posible frente a los demás. Particularmente, las primeras se disponen como la totalidad de los medios dispuestos estratégicamente para poner en funcionamiento el poder (instrumentarlo) o mantenerlo.

Las relaciones de poder implican entonces estrategias de luchas, sin embargo, las primeras no tienen como objetivo principal alcanzar una victoria total o sometimiento en su despliegue ya que es necesario en su cálculo considerar que las luchas posibles no se agotan o que existen medios para escapar a las propias relaciones de poder. Foucault comenta que "Cada relación de poder implica, al menos in potentia, una estrategia de lucha, en que dos fuerzas no se sobrepujan, no pierden su naturaleza específica, o no terminan finalmente confundidas entre sí". ${ }^{40} \mathrm{Si}$ bien se presenta esta distinción, la relación entre relaciones de poder y estrategias es de tensión, y una tiende a invocar o desviarse hacia la otra.

La confrontación alcanza su límite, y su término en cuanto relación, con la victoria y el emplazamiento de un mecanismo estable por sobre las reacciones libres de los adversarios. Se utiliza así una herramienta para dirigir de manera regular, constante y con razonable certeza la conducta de los otros. La finalidad de las relaciones de confrontación, a la vez su cumplimiento y suspensión, es la fijación de una relación de poder. Por su parte, las relaciones de poder también se ven inclinadas conjeturar una estrategia triunfador que deje de lado la manipulación e inducción de la conducta de los otros de manera calculada, para acomodar las reacciones de los adversarios ante los acontecimientos de manera más directa.

Las relaciones de poder pueden sintetizarse así como un conjunto de actividades que afectan a otras, vinculado sujetos entre sí mediante un juego de acción y reacción dispuesto por el cálculo y estrategias en un campo posible de actuaciones. Partiendo de

\footnotetext{
${ }^{39}$ Ibid. p 258

${ }^{40}$ Ibíd. p. 258 Las cursivas corresponden al texto original
} 
Nuevo Itinerario Revista Digital de Filosofía ISSN 1850-3578 2015 - Vol. 10 - Número X Resistencia, Chaco, Argentina

una base más empírica que buque vincular la relación entre teoría y práctica, la propuesta foucaultiana se dirige así hacia una “(...) nueva economía de las relaciones de poder". 41

Dicha economía debe considerar que, en su conjunto, las relaciones de poder precisan establecer un sistema de diferenciación que autoriza a actuar sobre las acciones de los demás, sea por medio de la desigualdad de riquezas, competencias, etc. Es la distinción mencionada la que permite alcanzar diferentes objetivos, como por ejemplo la acumulación de beneficios o el mantenimiento de privilegios. Los medios por los cuales se ejerce el poder son variables, no dependiendo así exclusivamente de la amenaza de las armas e incluyendo los efectos simbólicos. Dichos mecanismos pueden presentarse bajo diferentes formas de institucionalización, siendo el Estado un sistema complejo compuesto de aparatos múltiples, con grados de racionalización variables. Esto significa que la lógica del ejercicio del poder no responde simplemente a un derecho institucional o una estructura general homogénea, siendo la misma continuamente elaborada, transformada y organizada según lo requiera la situación e instituciones. Por ejemplo, una estrategia puede ser preparada en torno de la efectividad de los resultados antes que en relación con el costo o a la inversa. ${ }^{42}$

\section{A modo de conclusión}

Es posible establecer semejanzas en el estudio que realiza Pierre Bourdieu y Michel Foucault al considerar ciertos núcleos temáticos en el modo de analizar la problemática. Con respecto al abordaje del poder pueden destacarse tres conjeturas compartidas. La primera es la pluralidad, ya que ambos autores rechazan la posibilidad de abordar la temática desde una postura esencialista o metafísica donde el poder sea considerado un elemento uniforme y estático desde el cual deriven formas menores o subordinadas. La segunda la constituyen las prácticas, ya que atendiendo a las mismas pueden registrarse las heterogeneidades y transformaciones que el objeto de estudio presenta. El último supuesto corresponde a la función básica de dicha práctica,

\footnotetext{
${ }^{41}$ Ibíd. p. 243

${ }^{42}$ Cfr. Ibíd. p.p. 256 y 257. Sobre el último punto puede ser esclarecedor recordar el siguiente tipo de interrogantes presentes en los dispositivos de seguridad: “¿Es más costosa una represión severa y rigurosa, un represión blanda, una represión de tipo ejemplar y discontinuo o, al contrario, una represión continua? ¿Cuál es, entonces, el costo comparado del robo y represión? ¿Qué vale más: aflojar un poco el robo o la represión?" Foucault, Michel. Seguridad, Territorio, Población. Trad. Horacio Pons. Fondo de Cultura Económica, Bs As, 2006. p. 20
} 
Nuevo Itinerario Revista Digital de Filosofía ISSN 1850-3578 2015 - Vol. 10 - Número X Resistencia, Chaco, Argentina

distinguiéndola principalmente por establecer un modo de relación entre sujetos que pretende distintas finalidades.

También es posible destacar tres conceptos recurrentes y cardinales en ambos autores para analizar las prácticas que involucran relaciones de poder: economía, estrategia y libertad. Así, las relaciones de poder se establecen cuando ciertos individuos pueden afectar las acciones de otros. Dicha relación implica una imposición por parte de un sujeto o grupo que se desarrolla a partir de una desigualdad o distinción (sea de bienes, capacidades, autoridad, etc.); la misma se encuentra administrada desde una economía que permite gestionar los medios para actuar de un modo óptimo (aunque corresponde a cada caso particular establecer lo que se considera óptimo), y responde a una estrategia como una estimación en un juego de acción y reacción entre agentes relativamente libres que no agota la totalidad de las acciones posibles.

Es posible establecer un último punto de comparación con respecto a la diferencia que realizan los autores entre las formas de violencia física o material y los medios en que se ejerce el poder, ya que si bien reconocen que están vinculadas, la primera no representa el trasfondo oculto de la otra sino simplemente una administración poco efectiva (en el sentido del gasto o eficacia) de las relaciones de poder.

Para finalizar, cabe distinguir que los autores no reconocen la misma importancia a los intercambios simbólicos dados en la comunicación. Si bien Foucault los menciona y representan una parte específica en el estudio del poder, es en Bourdieu que los mismos adquieren una importancia cardinal ya que actualizan las relaciones entre los distintos actores sociales.

El presente artículo no agota la posibilidad de establecer futuras comparaciones entre los autores. Ya que es viable tomar las indicaciones de Foucault con respecto al capital humano presente en el neoliberalismo y confrontarlo con las formas de maximizar beneficios en la correlación de capitales en Bourdieu. También es posible relacionar las consideraciones sobre el lenguaje y el habla autorizado en el segundo autor con una obra anterior de Foucault titulada El orden del discurso, aunque cabe destacar que dicho escrito parte desde una perspectiva diferente sobre las relaciones de poder.

\section{Bibliografía}


Nuevo Itinerario Revista Digital de Filosofía ISSN 1850-3578 2015 - Vol. 10 - Número X Resistencia, Chaco, Argentina

- Castro, Edgardo. Lecturas Foucaulteanas. Una historia conceptual de la Biopolítica. UNIPE, La Plata, 2011.

- Foucault, Michel. El poder, una bestia magnífica. Sobre el poder, la prisión y la vida. Trad. Horacio Pons, Siglo Veintiuno, Bs As, 2012

- Foucault, Michel. El Sujeto y el Poder. En: Dreyfus, Hubert y Rabinow, Paul. Michel Foucault: más allá del estructuralismo y la hermenéutica. Trad. Rogelio C. Paredes. Nueva Visión, Buenos Aires, 2001.

- Foucault, Michel. "Entrevista sobre la prisión: el libro y su método". Trad. Fernando Álvarez Uría y Julia Varela. En: Foucault, Michel. Obras Esenciales. Madrid, Paidos, 2010

- Foucault, Michel. Seguridad, Territorio, Población. Trad. Horacio Pons. Fondo de Cultura Económica, Bs As, 2006.

- Foucault, Michel y Deleuze, Gilles. "Los intelectuales y el poder”. Trad. Fernando Álvarez Uría y Julia Varela. En: Foucault, Michel. Obras Esenciales. Madrid, Paidos, 2010

- Bourdieu, Pierre. El sentido práctico. Trad. Ariel Dilon. Bs As, Siglo XXI, 2010

- Bourdieu, Pierre. ¿Qué significa hablar? Economía de los intercambios linguisticos. Trad. Esperanza Martínez Pérez. Madrid, Akal, 1999.

- Bourdieu, Pierre. "Sobre el poder simbólico", en: Intelectuales, política y poder. Trad. Alicia B. Gutiérrez. Bs As, Eudeba, 2005

- Nosseto, Luciano Ezequiel. Discursos y estrategias. Michel Foucault y la política. Tesis para optar por el título de Doctor en Ciencias Sociales. S/E, Facultad de Ciencias Sociales, Universidad de Buenos Aires, 2010. 